\title{
Parent-Adolescent Interactions and Substance Use: A Prospective, Observational Study of Mexican Origin Families
}

\author{
D. Angus Clark \\ University of Michigan \\ M. Brent Donnellan \\ Michigan State University \\ Richard W. Robins \\ University of California, Davis
}

\section{Acknowledgements}

This research was supported by a grant from the National Institute on Drug Abuse (DA017902)

to Richard W. Robins and Rand D. Conger. We thank the participating families, staff, and research assistants who took part in this study. Address correspondence to D. Angus Clark, Department of Psychiatry, Addiction Center, University of Michigan, Rachel Upjohn Building, 4250 Plymouth Rd., Ann Arbor, MI 48109. Electronic mail may be sent to cladavid@med.umich.edu. 


\begin{abstract}
Parent-adolescent relationship quality is a predictor of adolescent substance use. However, most research in this area has relied on questionnaire based assessments of both substance use and interpersonal family dynamics. Furthermore, prior work has typically focused on European American samples. These gaps are addressed in the current study via the evaluation of the prospective associations between observed parent-adolescent interactions in $7^{\text {th }}$ grade, and substance use in $9^{\text {th }}$ and $12^{\text {th }}$ grade, in a longitudinal sample of Mexican-origin youth $(N=674)$. Adolescents' observed behaviors towards parents were weakly but significantly predictive of future substance use, especially observed hostility. Results add to the literature suggesting that family processes are relevant in the development of substance use, and offer converging evidence regarding the role of early aggressive tendencies and later substance use.

Keywords: adolescence, substance use, parent-adolescent relationship, family processes, observational assessment
\end{abstract}




\section{Introduction}

Substance abuse is associated with many adverse mental and physical health outcomes (Mathers et al., 2006; Rooke, Norberg, Copeland, \& Swift, 2013; Steinhausen, Eschmann, \& Metzke, 2007). An early age at initiation is a relatively strong predictor of later substance abuse (Flory et al., 2004; Georgiades \& Boyle, 2007; Tucker et al., 2005), which suggests that a developmental perspective might provide important insights into the etiology of substance abuse. The present investigation specifically examines how observed interaction patterns between early adolescents and their parents, and the overall quality of the parent-adolescent relationship, predict substance use in a longitudinal sample of Mexican-origin youth.

Most developmental models of substance use implicate both dispositional and contextual factors (e.g., Conger, 1997; Petraitis, Flay, \& Miller, 1995; Wills \& Dishion, 2004; Wills, Sandy, \& Yaeger, 2000). With most youth still living at home with their parent(s), the family environment is one important context to consider (Conger, 1997; Wills \& Yaeger, 2003). The quality of the parent-adolescent relationship specifically is likely one especially consequential aspect of the family environment in this regard (Ryan, Jorm, \& Lubman, 2010). For example, a positive relationship may be crucial for instilling conventional, anti-substance use convictions in adolescents, whereas a negative relationship may push adolescents toward substance use (Conger, 1997; Petraitis et al., 1995).

Prior research does support the idea that a positive parent-adolescent relationship is associated with less substance use, whereas a negative relationship puts youth at risk (Ryan et al., 2010; Wills \& Yaeger, 2003). Meta-analytic evidence for example indicates that a positive parent-adolescent relationship predicts a later age of alcohol use initiation, and less problematic alcohol use later in life (Ryan et al., 2010). There is also evidence that parent-adolescent 
relationship quality predicts the future use of tobacco, marijuana, and other illicit substances (Branstetter, Low, \& Furman, 2011; Ledoux, Miller, Choquet, \& Plant, 2002). Moreover, intervention programs that improve the quality of the parent-child relationship have been shown to both delay the onset, and reduce the rate, of substance use (Spoth, Redmond, \& Shin, 2001).

Considering the overall quality of the parent-adolescent relationship is useful as this construct represents a holistic composite of many family processes. However, it is also important to consider more specific aspects of the parent-adolescent relationship. For instance, parental warmth, support, and positive communication appear to be protective factors against substance use, whereas conflict increases risk (McMaster \& Wintre, 1996; Ryan, Jorm, \& Lubman, 2010; Wills \& Yaeger, 2003). Although most frequently studied in majority European or EuropeanAmerican samples, these relations appear to broadly generalize to other populations. For example, positive and warm communication patterns predict decreased substance use in Mexican origin and other ethnic minority samples (Griffin et al., 2000; Marsiglia, Nagoshi, Parsai, \& Castro, 2014). Likewise, conflict between Mexican-origin youth and their parents predicts increased substance use (Marsiglia et al., 2010; Pasch et al., 2006). Notably though, Marsiglia and colleagues (2014) also found that parents' acculturation status moderated the relation between parents' behavior and substance use (e.g., communication was more strongly related to girls' cigarette usage when parents were more acculturated). These results compliment research showing that $1^{\text {st }}$ generation Mexican-American adolescents report less substance use than $2^{\text {nd }}$ and $3^{\text {rd }}$ generation Mexican-American adolescents (e.g., Hussey et al., 2007), and emphasizes the importance of considering cultural background and nativity status when examining parentadolescent dynamics and substance use. 
Importantly, most studies in this area rely on parent and/or adolescent reports of the parent-adolescent relationship, and adolescent reports of substance use. This raises concerns about shared method variance when interpreting the correlations of some studies. Moreover, even when there is not an issue with reporter overlap, there is a chance that youth that use substances (and their parents) may provide negatively biased reports of their interactions. Thus, it is important to supplement report-based work with research using alternative methods for assessing parent-child interactions. One potentially useful alternative approach is to study family interactions and their outcomes with observational data (Hops et al., 1990). In addition to the work by Conger and colleagues (e.g., Conger et al., 1991), we know of only a handful of studies that take an observational approach to studying parent-adolescent interactions and their associations with substance use. Hops and colleagues (1990) for example found that observed adolescent aversive affect (e.g., aggression and irritability), and paternal positive affect, predicted tobacco and marijuana use. Chaplin and colleagues (2012), on the other hand, found no evidence linking observed behaviors in a parent-adolescent interaction session to adolescent substance use.

Thus, there is a need for more research that evaluates the associations between observed parent-adolescent interactions and substance use, especially using diverse samples. The existing studies are either conducted with mostly European American families, cross-sectional, and/or based on relatively small sample sizes. We thus add to this literature by testing associations between observed parent-adolescent interactions and substance use in a large, longitudinal sample of Mexican-origin adolescents. We also examine how parent and youth reports of their overall relationship quality predict substance use; this provides a contrast between observational and report methods, and between specific interactive behaviors and family members' subjective 
experience of the family environment. Finally, we test whether adolescent gender or nativity status (i.e., born in the United States or not) moderates any of the associations between the family variables and substance use. Based on prior research, we expected observed warmth, and a more positive overall relationship, to predict less future substance use, and observed hostility to predict more future substance use. No predictions were made regarding moderation effects. Overall, this prospective, multi-method approach to studying family dynamics and adolescent substance use adds to the existing literature and offers a way to estimate how methodological factors influence correlational results.

\section{Method}

\section{Participants and Procedures}

The data come from the California Families Project, a longitudinal study of 674 Mexicanorigin youth (50\% girls) and their parents. To recruit participants, children were drawn at random from rosters of students in the Sacramento and Woodland, CA, school districts. The focal child had to be in the $5^{\text {th }}$ grade, living with her or his biological mother $(82 \%$ of youth come from two parent households), and of Mexican origin (i.e. of Mexican ancestry; $72 \%$ of youth were born in

the United States). The first assessment occurred when the youth were in $5^{\text {th }}$ grade $\left(\mathrm{M}_{\text {age }}=10.40\right.$ years, $S D=0.61)$.

Participants were interviewed in their homes in Spanish or English, depending on preference. The parents were not present when their child was interviewed. To collect the observational data, families participated in 20-minute video recorded tasks. Parent-adolescent dyads (mother-adolescent, father-adolescent) were instructed to discuss their life together. Cue cards with relevant questions were provided to facilitate discussion. During these sessions the interviewer and other parent (if a two-parent family) were absent. These sessions were rated by 
trained coders. Coders were trained over a 2-3 month period, and subsequently participated in recurring training sessions to prevent drift. Videos were randomly assigned to each coder.

The current study is based on observational and relationship quality data from the $7^{\text {th }}$ grade assessment $\left(\mathrm{M}_{\mathrm{age}}=12.80\right.$ years, $\left.S D=0.49\right)$, and substance use data from the $9^{\text {th }}\left(\mathrm{M}_{\mathrm{age}}=\right.$ 14.27 years, $S D=0.53)$ and $12^{\text {th }}$ grade assessments $\left(M_{\text {age }}=17.69\right.$ years, $\left.S D=0.48\right)$. Seventh grade substance use data were also included as control variables. The $7^{\text {th }}$ grade observational and relationship quality data were used because they come from when participants were just entering adolescence. The $9^{\text {th }}$ and $12^{\text {th }}$ grade substance use data were used because these waves represent the beginning and end of high school. These are also major milestones of adolescence, and span a time in the lifespan when rates of substance use typically increase (SAMHSA, 2014). At the $7^{\text {th }}$ grade assessment, 532 youth, 522 mothers, and 288 fathers participated in the observational assessments; 576 youth, 574 mothers, and 384 fathers provided reports on relationship quality. In $9^{\text {th }}$ grade, 604 youths provided information on substance use, and in the $12^{\text {th }}$ grade, 600 did. The adolescents for whom fathers were present did not generally differ in their rates of substance use compared to those whose fathers were not (Cohen's $d$ s range from .06 to .22 ).

\section{Measures}

Observed warmth and hostility. Interactive sessions were rated using the Iowa Family Interaction Rating Scales (IFIR; Melby \& Conger, 2001). The IFIR is a coding system designed to assess the nature of behavioral exchanges, and overall family processes. This coding system is a valid, well-established method for capturing various family dynamics (Melby \& Conger, 2001), and is widely used to study the antecedents and consequences of parent-child, and romantic partner, interactions (e.g., Conger et al., 2003; Donnellan et al., 2004; Mathews et al., 1996; Thornberry, 2005). The IFIR includes twelve dyadic interaction scales. Observers score 
each code on a 1-9 scale, 9 indicating stronger or more frequent evidence. These twelve scales were used to create two composites, warmth and hostility. These composites were created by averaging together the scores of individual scales. Overall, four composites were created: one from the adolescent to each of the parents (e.g., adolescents' hostility towards mothers), and one from each parent to the adolescent (e.g., mothers' warmth towards adolescents).

Relationship quality. Relationship quality was assessed with a 3 or 4 item scale (depending on informant; mothers and fathers completed a 4 item scale, youth completed the 3 item scale) that was originally developed for use within the Iowa Youth and Families Project (later the Family Transitions Project; Elder \& Conger, 2000). This scale is meant to serve as an overall evaluative judgement of the relationship between parents and their children. Adolescents filled out this questionnaire in reference to both their mothers and fathers, and mothers and fathers filled out this questionnaire in reference to the target adolescent. Participants responded on a four point scale ranging from 1 "Very dissatisfied" to 4 "Very Satisfied". Sample items include "How satisfied are you with relationship with your mom/dad" and "During the past 12 months, has being a parent to [target adolescent] been an enjoyable experience"? Scores were computed by summing up the individual item responses.

Substance use. The 18-item Alcohol, Tobacco, and Other Drug Use scale, adapted from Elliott, Huizinga, and Ageton (1985), measures lifetime use of a wide range of substances, as well as recent frequency of substance use. The first 9 items were used to measure lifetime substance use. Participants responded "yes" or "no" to questions such as, "Have you ever used or tried cigarettes?", and "Have you ever used or tried beer - more than just a few sips?" "Yes" responses were coded as 1s, and "no" responses were coded as 0s. Responses across the scale were summed up to generate a total lifetime substance use score. The second 9 items were used 
to measure the frequency of substance use over the past 3 months. Participants responded to questions such as, "In the past 3 months, how many times have you used or tried cigarettes" on a 5 point scale that ranged from 0 ("never") to 4 (“almost every day"). Responses across the scale were summed up to generate a total substance use frequency score.

\section{Results}

We set an alpha level of .05 to determine statistical significance but focus on effect sizes. We use the conventional rule of thumb whereby correlations around $|.10|$ are considered small and correlations around $|.30|$ are considered moderate (e.g., McCartney \& Rosenthal, 2000). Descriptive statistics and intercorrelations for observed warmth and hostility, and relationship quality, are reported in Table 1. Observed behaviors and reports of relationship quality were associated with small to moderate correlations that ranged from .15 to .30 . Intercorrelations among the observed behavior variables ranged from .01 to .50; the highest associations were between adolescents' corresponding behaviors towards mothers and fathers (e.g., hostility towards mothers and fathers). Descriptive statistics for the substance use variables can be found in Table 2. At $9^{\text {th }}$ grade, slightly more than half the sample reported no lifetime substance use, and most of the sample reported no use over the past 3 months. As would be expected, scores on the substance use variables increased over time. By $12^{\text {th }}$ grade, more than $50 \%$ of participants reported having used at least one substance at some point, and around $40 \%$ reported using substances in the past 3 months. Consistent with prior research, adolescents born in the U.S. reported more substance use in both $9^{\text {th }}$ and $12^{\text {th }}$ grade compared to adolescents born in Mexico, however these differences were small (Cohen's $d$ s from .04 to .21).

Table 2 shows the correlations between observed behavior and substance use in $9^{\text {th }}$ grade, as well as standardized regression coefficients controlling for prior substance use in $7^{\text {th }}$ grade. 
Observed adolescent behavior was somewhat related to lifetime substance use, but not recent substance use frequency. Youth who exhibited warm behavior toward their mothers during the $7^{\text {th }}$ grade interaction task were less likely to have ever used substances in $9^{\text {th }}$ grade. Conversely, youth hostility toward mothers and fathers was significantly associated with more lifetime substance use by $9^{\text {th }}$ grade. After controlling for prior $\left(7^{\text {th }}\right.$ grade $)$ lifetime substance use and frequency, the findings for observed hostility remained significant (albeit attenuated) whereas those for observed warmth did not. Parents' observed behaviors towards their adolescents were negligibly associated with the $9^{\text {th }}$ grade substance use variables, with correlations ranging from .01 to .06 (mean $r=.03)$.

Table 2 also shows associations between observed behavior in $7^{\text {th }}$ grade, and $12^{\text {th }}$ grade substance use. Effect sizes were smaller than those for $9^{\text {th }}$ grade substance use, however these differences were not statistically significant (see Table 2). Adolescent hostility towards mothers was again significantly associated with lifetime substance use, and this association remained significant after controlling for $7^{\text {th }}$ grade substance use. No other observed behaviors significantly predicted substance use. Correlations across all family members ranged in size from .00 to .11 (mean $r=.05)$.

Relationship quality in $7^{\text {th }}$ grade was negatively associated with both substance use outcomes in $9^{\text {th }}$ grade, regardless of whether it was reported by adolescents, mothers, or fathers. Correlations ranged in size from .10 to .15 (mean $r=.13$ ), indicating small effects. In $12^{\text {th }}$ grade, all informants' reports of relationship quality were again significantly, negatively associated with lifetime substance use, but only mothers' and fathers' reports predicted recent substance use frequency. Correlations ranged in size from .00 to .16 (mean $r=.11$ ), again indicating relatively 
small effects overall. Importantly, these correlations were often substantially reduced, several to non-significance, after controlling for $7^{\text {th }}$ grade substance use (see Table 2).

Finally, a series of multiple regression models were run to test whether results were moderated by either adolescent sex or nativity status (i.e., born in the U.S or not). There was some evidence of gender moderation such that girls' observed warmth towards fathers was consistently more predictive of future substance use than boys' observed warmth towards fathers. There was no evidence that nativity status moderated the findings discussed here.

\section{Discussion}

We evaluated how different aspects of the parent-adolescent relationship prospectively predicted substance use behaviors using data from a large, multi-informant and longitudinal study of Mexican-origin youth and their families. Interactive behaviors and relationship quality were measured when the adolescents were in $7^{\text {th }}$ grade, and substance use variables were measured when the adolescents were in $9^{\text {th }}$ grade, and again when they were in $12^{\text {th }}$ grade.

Observed behaviors in $7^{\text {th }}$ grade were associated with some future substance use variables, but effect sizes were small, and varied across family member. Adolescents' observed behaviors towards parents were more strongly associated with substance use than parents' observed behaviors towards adolescents in $9^{\text {th }}$ grade (mean $r$ s .09 versus .03 ), but not necessarily in $12^{\text {th }}$ grade (mean $r s .05$ versus .05). This suggests that when it comes to interactions between adolescents and parents, adolescent behaviors may be more likely to be predictive of substance use than parents' behaviors. This is similar to what was found by Hops and colleagues (1990). Specifically, the observed behaviors of adolescents were more predictive of substance use than parents' behaviors. Our study extends these findings by demonstrating that the observed behaviors of adolescents have modest predictive power several years into the future. 
Adolescent behavior in $7^{\text {th }}$ grade was more weakly associated with the substance outcomes in $12^{\text {th }}$ grade than $9^{\text {th }}$ grade, though generally not significantly so. The relation between observed hostility towards the mother and lifetime substance use was especially persistent across high school, even when controlling for $7^{\text {th }}$ grade substance use. This compliments other work suggesting that higher levels of aggression in early life, and increased parent-adolescent conflict, are associated with more substance use (e.g., Clark, Donnellan, Robins, \& Conger, 2015; Marsiglia et al., 2010). This result also mirrors what was found by Hops and colleagues (1990) when using a similar observational task. Taken together, these findings paint a multi-method picture in which adolescent aggression and hostility is longitudinally predictive of substance use. It is intriguing though that in the current study hostility towards the mother was more predictive of substance use than hostility towards the father. Some of this may stem from the overall lower rates of hostile behaviors exhibited towards fathers (see Table 1). Youths may be less inclined to act hostile towards their fathers than their mothers, regardless of aggressive tendencies. Also, fewer fathers participated in the interactive sessions than mothers, reducing the statistical power to detect what are small effects.

Reports of relationship quality were more strongly and consistently related to substance use than were observed behaviors. These reports supplement variables based on individual behaviors by capturing overarching impressions of the parent-adolescent relationship. The quality of the parent-adolescent relationship was measured in $7^{\text {th }}$ grade, and we found that a positive relationship at this point was associated with less substance use through the end of high school. Furthermore, this relation held regardless of which family member served as an informant of relationship quality. However, relationship quality was much more weakly associated with substance use when concurrent (i.e., $7^{\text {th }}$ grade) substance use was controlled for. 
In other words, the variance in relationship quality that predicted later substance use tended to be shared with early substance use. This study thus provides some support for the notion that the parent-adolescent relationship in early adolescence can be predictive of later substance use (Branstetter et al., 2011; Ledoux et al., 2002; Ryan et al., 2010), and that prior work on the topic, mostly based on European American or European samples, generalizes to Mexican-origin youth.

The current results contribute to the literature by building on the small body of research using observational techniques to examine how specific family dynamics relate to substance use. Nonetheless, there are limitations to the current study that must be acknowledged. First, our observational variables were based on a single, 20 minute interaction session between adolescents and parents. This provides only a very narrow window into family dynamics and may contribute to smaller effect size estimates. Longer sessions, and/or more of them, would be preferable, and likely make it easier to detect any associations between substance use and patterns of interaction. Also, we relied exclusively on youth reports to measure substance use.

In closing, we found evidence in a longitudinal study of Mexican origin families that observed parent-adolescent interactions, and parents' and adolescents' reports of the parentadolescent relationship quality, prospectively predict substance use outcomes in $9^{\text {th }}$ and $12^{\text {th }}$ grade to a mild degree. Noteworthy is the finding that adolescent hostility towards parents during a 20 minute interaction session in $7^{\text {th }}$ grade is predictive of substance use years into the future. This further emphasizes that interpersonal aggressiveness may be an early emerging risk factors for substance use (e.g., Clark et al., 2015). These findings methodologically extend work on associations between the family climate and substance use in adolescents, and provide evidence that previously investigated associations along these lines generalize to Mexican origin youth. 


\section{References}

Branstetter, S. A., Low, S., \& Furman, W. (2011). The influence of parents and friends on adolescent substance use: A multidimensional approach. Journal of Substance Use, 16(2), 150-160. doi: 10.3109/14659891.2010.519421

Chaplin, T. M., Sinha, R., Simmons, J. A., Healy, S. M., Mayes, L. C., Hommer, R. E., \& Crowley, M. J. (2012). Parent-adolescent conflict interactions and adolescent alcohol use. Addictive Behaviors, 37, 605-612. doi: 10.1016/j.addbeh.2012.01.004

Clark, D. A., Donnellan, M. B., Robins, R. W., \& Conger, R, D. (2015). Early adolescent temperament, parental monitoring, and substance use in Mexican-origin adolescents. Journal of Adolescence, 41, 121-131. doi:10.1016/j.adolescence.2015.02.010

Conger, R. D. (1997). The social context of substance abuse: A developmental perspective. In Rural Substance Abuse: State of Knowledge and Issues (pp. 6-36).

Conger, R. D., Lorenz, F. O., Elder, G. H., Melby, J. N., Simons, R. L., \& Conger, K. J. (1991). A process model of family economic pressure and early adolescent alcohol use. Journal of Early Adolescence, 11(4), 430-449.

Conger, R. D., Neppl, T., Kim, K. J., \& Scaramella, L. (2003). Angry and aggressive behavior across three generations: A prospective, longitudinal study of parents and children. Journal of Abnormal Child Psychology, 31(2), 143-160.

Donnellan, M. B., Conger, R. D., \& Bryant, C. M. (2004). The Big Five and enduring marriages. Journal of Research in Personality, 38, 481-504. doi: 10.1016/j.jrp.2004.01.001

Eaton, D. K., Kann, L., Kinchen, S., Shanklin, S., Ross, J., Hawkins, J., . . W Wechsler, H. (2008). Youth risk behavior surveillance---United States, 2007. Morbidity and Mortality Weekly Report, 57(SS04), 1-131. 
Elder, G. H., \& Conger, R. D. (2000). Children of the Land: Adversity and success in rural America. Chicago, IL: University of Chicago Press.

Elliott, D.S., Huizinga, D., \& Ageton, S.S. (1985). Explaining delinquency and drug use. Beverly Hills, CA; Sage.

Fergusson, D. M., \& Boden, J. M. (2008). Cannabis use and later life outcomes. Addiction, 103, 969-976. doi: 10.1111/j.1360-0443.2008.02221.x

Flory, K., Lynam, D., Milich, R., Leukefeld, C., \& Clayton, R. (2004). Early adolescent through young adult alcohol and marijuana use trajectories: Early predictors, young adult outcomes, and predictive utility. Development and Psychopathology, 16, 193-213. doi: $10.1017 /$ S0954579404044475

Georgiades, K., \& Boyle, M. H. (2007). Adolescent tobacco and cannabis use: Young adult outcomes from the Ontario Child Health Study. Journal of Child Psychology and Psychiatry, 48(7), 724-731. doi: 10.1111/j.1469-7610.2007.01740.x

Griffin, K. W., Botvin, G. J., Scheier, L. M., Diaz, T., \& Miller, N. L. (2000). Parenting practices as predictors of substance use, delinquency, and aggression among urban minority youth: Moderating effects of family structure and gender. Psychology of Addictive Behavior, 14(2), 174-184.

Hops, H., Tildesley, E. A., Lichtenstein, E., Ary, D., Sherman, L. (1990). Parent-adolescent problem-solving interactions and drug use. American Journal of Drug and Alcohol Abuse, 16, 239-258.

Ledoux, S., Miller, P., Choquet, M., \& Plant, M. (2002). Family structure, parent-child Relationships, and alcohol and other drug use among teenagers in France and the United Kingdom. Alcohol \& Alcoholism, 37(1), 52-60. 
Marsiglia, F. F., Kulis, S., Parsai, M., Villar, P., \& Garcia, C. (2010). Cohesion and conflict: Family influences on adolescent alcohol use in immigrant Latino families. Journal of Ethnicity in Substance Abuse, 8(4), 400-412. doi: 10.1080/15332640903327526

Marsiglia, F. F., Nagoshi, J. L., Parsai, M., \& Castro, F. G. (2014). The effects of parental acculturation and parenting practices on the substance use of Mexican-heritage adolescents from Southwestern Mexican Neighborhoods. Journal of Ethnicity in Substance Use, 13(3), 288-311. doi: 10.1080/15332640.2014.905215

Mathers, M., Toumbourou, J. W., Catalano, R. F., Williams, J., \& Patton, G. C. (2006). Consequences of youth tobacco use: A review of prospective behavioral studies. Addiction, 101, 948-958. doi: 10.1111/j.1360-0443.2006.01438.x

Matthews, L. S., Conger, R. D., \& Wickrama, K. A. S. (1996). Work-family conflict and marital quality: Mediating processes. Social Psychology Quarterly, 59(1), 62-79.

McCartney, K., \& Rosenthal, R. (2000). Effect size, practical importance, and social policy for children. Child Development, 71(1), 173-180.

McMaster, L. E., \& Wintre, M. G. (1996). The relations between perceived parental reciprocity, perceived parental approval, and adolescent substance use. Journal of Adolescent Research, 11(4), 440-460.

Melby, J. N., Conger, R. D. (2001). The Iowa Interaction Rating Scales: Instrument summary. In: Family Observational Coding Systems: Resources for Systematic Research. Mahwah, NJ: Erlbaum.

Mercado-Crespo, M. C., Mbah, A. K. (2013). Race and ethnicity, substance use, and physical aggression among U.S. high school students. Journal of Interpersonal Violence, 28, 1367-1384. doi: 10.1177/0886260512468234 
Neighbors, B. D., Clark, D. B., Donovan, J. E., \& Brody, G. H. (2000). Difficult temperament, parental relationships, and adolescent alcohol use disorder symptoms. Journal of Child \& Adolescent Substance Abuse, 10(1), 69-86. doi: 10.1300/J029v10n0105

Pasch, L. A., Deardorff, J., Tschann, J. M., Flores, E., Penilla, C., \& Pantoja, P. (2006). Acculturation, parent-adolescent conflict, and adolescent adjustment in Mexican American families. Family Processes, 45(1), 75-86.

Petraitis, J., Flay, B. R., \& Miller, T. Q. (1995). Reviewing theories of adolescent substance use: Organizing pieces in the puzzle. Psychological Bulletin, 117(1), 67-86.

Rooke, S. E., Norberg, M. M., Copeland, J., \& Swift, W. (2013). Health outcomes associated with long-term regular cannabis and tobacco smoking. Addictive Behaviors, 38, 2207-2213.

Ryan, S. M., Jorm, A. F., \& Lubman, D. I. (2010). Parenting factors associated with reduced adolescent alcohol use: A systematic review of longitudinal studies. Australian and New Zealand Journal of Psychiatry, 44, 774-783.

Spoth, R. L., Redmond, C., Shin, C. (2001). Randomized trial of brief family interventions for general populations: Adolescent substance use outcomes 4 years following baseline. Journal of Counseling and Clinical Psychology, 69(4), 627-642. doi: 10.1037//0022-006X.69.4.627

Substance Abuse and Mental Health Services Administration (2014). Results from the 2013 National Survey on Drug Use and Health: Mental Health Findings. NSDUH Series H-47, HHS Publication No. (SMA) 13-4805. Rockville, MD: Substance Abuse and Mental Health Services Administration.

Steinhausen, H. C., Eschmann, S., \& Metzke, C. W. (2007). Continuity, psychosocial 
correlates, and outcome of problematic substance use from adolescence to young adulthood in a community sample. Child and Adolescent Psychiatry and Mental Health, 1, 12-21. doi: 10.1186/1753-2000-1-12

Thornberry, T. P. (2005). Multiple patterns of offending across the life course and across generations. The Annals of the American Academy of Political and Social Science, $602,156-195$

Tucker, J. S., Ellickson, P. L., Orlando, M., Martino, S. C., \& Klein, D. J. (2005). Substance use trajectories from early adolescence to emerging adulthood: A comparison of smoking, binge drinking, and marijuana use. The Journal of Drug Issues, 35(2), 307-332.

U.S. Census. (2011). Overview of race and Hispanic origin: 2010.

Wills, T. A., \& Dishion, T. J. (2004). Temperament and adolescent substance use: A transactional analysis of emerging self-control. Journal of Clinical Child \& Adolescent Psychology, 33(1), 69-81. doi: 10.1207/S15374424JCCP3301_7

Wills, T. A., Sandy, J. M., \& Yaeger, A. (2000). Temperament and adolescent substance use: An epigenetic approach to risk and protection. Journal of Personality, 68(6), 1127-1151

Wills, T. A., \& Yaeger, A. M. (2003). Family factors and adolescent substance use: Models and mechanisms. Current Directions in Psychological Science, 12(6), 222-226. 
Table 1

Descriptive Statistics for Observed Interactions and Reported Relationship Quality

\begin{tabular}{|c|c|c|c|c|c|c|c|c|c|c|c|c|}
\hline & 1 & 2 & 3 & 4 & 5 & 6 & 7 & 8 & 9 & 10 & 11 & 12 \\
\hline \multicolumn{13}{|l|}{ Observed Warmth } \\
\hline \multicolumn{13}{|l|}{ 1. Adolescent to Mother } \\
\hline 2. Adolescent to Father & $.44^{*}$ & & & & & & & & & & & \\
\hline 3. Mother to Adolescent & $.27 *$ & $.24 *$ & & & & & & & & & & \\
\hline 4. Father to Adolescent & $.16^{*}$ & $.30 *$ & $.17 *$ & & & & & & & & & \\
\hline \multicolumn{13}{|l|}{ Observed Hostility } \\
\hline 5. Adolescent to Mother & $-.09 *$ & .02 & -.07 & -.03 & & & & & & & & \\
\hline 6. Adolescent to Father & $-.13 *$ & .03 & -.01 & -.05 & $.50 *$ & & & & & & & \\
\hline 7. Mother to Adolescent & $-.10 *$ & $.13^{*}$ & .01 & .07 & $.50^{*}$ & $.26^{*}$ & & & & & & \\
\hline 8. Father to Adolescent & -.11 & -.07 & .03 & .04 & $.24 *$ & $.35^{*}$ & $.16^{*}$ & & & & & \\
\hline \multicolumn{13}{|l|}{ Relationship Quality } \\
\hline 9. Adolescent to Mother & $.28^{*}$ & $.18^{*}$ & $.15^{*}$ & .09 & $-.13 *$ & -.07 & $-.10 *$ & $-.15^{*}$ & & & & \\
\hline 10. Adolescent to Father & $.19 *$ & $.14^{*}$ & $.10^{*}$ & .08 & $-.18^{*}$ & $-.14 *$ & $-.20 *$ & $-.15^{*}$ & $.43^{*}$ & & & \\
\hline 11. Mother to Adolescent & .25 & $.12 *$ & $.17 *$ & $.13^{*}$ & $-.19 *$ & -.06 & $-.17 *$ & -.11 & $.28 *$ & $.18^{*}$ & & \\
\hline 12. Father to Adolescent & $.13^{*}$ & $.14^{*}$ & $.11^{*}$ & $.14^{*}$ & $-.18 *$ & $-.15^{*}$ & -.09 & -.05 & $.18^{*}$ & $.24 *$ & $.29 *$ & \\
\hline M & 3.97 & 3.96 & 4.23 & 3.95 & 2.43 & 2.09 & 2.84 & 2.58 & 10.38 & 9.87 & 14.61 & 14.88 \\
\hline SD & .90 & .94 & 1.01 & .98 & 1.08 & .86 & 1.04 & 1.01 & 1.42 & 1.79 & 1.63 & 1.33 \\
\hline
\end{tabular}

$\mathrm{M}=$ Mean; $\mathrm{SD}=$ Standard Deviation. Values come from $7^{\text {th }}$ grade assessment. $*=p<.05$ 
Table 2

Correlations between Observed Interactions and Relationship Quality in $7^{\text {th }}$ Grade and Substance Use in $9^{\text {th }}$ and $12^{\text {th }}$ Grade

\begin{tabular}{|c|c|c|c|c|}
\hline & \multicolumn{2}{|c|}{$9^{\text {th }}$ Grade } & \multicolumn{2}{|c|}{$12^{\text {th }}$ Grade } \\
\hline & $\begin{array}{c}\text { Lifetime } \\
\text { Substance } \\
\text { Use }\end{array}$ & $\begin{array}{l}\text { Substance } \\
\text { Use } \\
\text { Frequency }\end{array}$ & $\begin{array}{c}\text { Lifetime } \\
\text { Substance } \\
\text { Use }\end{array}$ & $\begin{array}{l}\text { Substance } \\
\text { Use } \\
\text { Frequency }\end{array}$ \\
\hline \multicolumn{5}{|l|}{ Adolescent to Mother } \\
\hline Observed Warmth & $\begin{array}{l}-.11 * \\
(-.08)\end{array}$ & $\begin{array}{c}-.07 \\
(-.06)\end{array}$ & $\begin{array}{c}-.07 \\
(-.05)\end{array}$ & $\begin{array}{c}-.03 \\
(-.03)\end{array}$ \\
\hline Observed Hostility & $\begin{array}{l}.12 * \\
(.09 *)\end{array}$ & $\begin{array}{c}.07 \\
(.06)\end{array}$ & $\begin{array}{l}.11^{*} \\
\left(.09^{*}\right)\end{array}$ & $\begin{array}{c}.00 \\
(.00)\end{array}$ \\
\hline Relationship Quality & $\begin{array}{l}-.10^{*} \\
(-.04)\end{array}$ & $\begin{array}{c}-.12 * \\
(-.10 *)\end{array}$ & $\begin{array}{c}-.13^{*} \\
\left(-.09^{*}\right)\end{array}$ & $\begin{array}{c}.00 \\
(.01)\end{array}$ \\
\hline \multicolumn{5}{|l|}{ Adolescent to Father } \\
\hline Observed Warmth & $\begin{array}{c}.05 \\
(.06)\end{array}$ & $\begin{array}{c}.06 \\
(.07)\end{array}$ & $\begin{array}{c}.04 \\
(.04)\end{array}$ & $\begin{array}{c}.07 \\
(.08)\end{array}$ \\
\hline Observed Hostility & $\begin{array}{l}.13^{*} \\
(.12)\end{array}$ & $\begin{array}{c}.08 \\
(.08)\end{array}$ & $\begin{array}{l}.05 \\
(.04)\end{array}$ & $\begin{array}{c}.02 \\
(.02)\end{array}$ \\
\hline Relationship Quality & $\begin{array}{l}-.14 * \\
(-.02)\end{array}$ & $\begin{array}{c}-.14 * \\
(-.09 *)\end{array}$ & $\begin{array}{l}-.15 * \\
(-.06)\end{array}$ & $\begin{array}{c}.02 \\
(.04)\end{array}$ \\
\hline \multicolumn{5}{|l|}{ Mother to Adolescent } \\
\hline Observed Warmth & $\begin{array}{l}-.01 \\
(.03)\end{array}$ & $\begin{array}{c}.01 \\
(.03)\end{array}$ & $\begin{array}{l}-.01 \\
(.02)\end{array}$ & $\begin{array}{c}.07 \\
(.09)\end{array}$ \\
\hline Observed Hostility & $\begin{array}{c}.06 \\
(.05)\end{array}$ & $\begin{array}{c}.06 \\
(.06)\end{array}$ & $\begin{array}{c}.04 \\
(.02)\end{array}$ & $\begin{array}{c}-.01 \\
(-.01)\end{array}$ \\
\hline Relationship Quality & $\begin{array}{l}-.15^{*} \\
(-.06)\end{array}$ & $\begin{array}{c}-.13 * \\
(-.09 *)\end{array}$ & $\begin{array}{l}-.14 * \\
(-.08)\end{array}$ & $\begin{array}{c}-.11 * \\
(-.09 *)\end{array}$ \\
\hline \multicolumn{5}{|l|}{ Father to Adolescent } \\
\hline Observed Warmth & $\begin{array}{c}-.02 \\
(-.02)\end{array}$ & $\begin{array}{l}-.01 \\
(-.02)\end{array}$ & $\begin{array}{c}-.08 \\
(-.08)\end{array}$ & $\begin{array}{c}.01 \\
(.01)\end{array}$ \\
\hline Observed Hostility & $\begin{array}{c}.04 \\
(.03)\end{array}$ & $\begin{array}{c}-.04 \\
(-.04)\end{array}$ & $\begin{array}{c}.09 \\
(.08)\end{array}$ & $\begin{array}{c}.10 \\
(.09)\end{array}$ \\
\hline Relationship Quality & $\begin{array}{l}-.12 * \\
(-.08)\end{array}$ & $\begin{array}{c}-.12 * \\
\left(-.10^{*}\right)\end{array}$ & $\begin{array}{c}-.16^{*} \\
(-.13 *)\end{array}$ & $\begin{array}{c}-.16^{*} \\
\left(-.15^{*}\right) \\
\end{array}$ \\
\hline M & $\begin{array}{l}1.06 \\
(.26)\end{array}$ & $\begin{array}{c}.66 \\
(.15)\end{array}$ & 1.98 & 1.27 \\
\hline SD & $\begin{array}{l}1.83 \\
(.87)\end{array}$ & $\begin{array}{l}1.93 \\
(.94)\end{array}$ & 1.98 & 2.77 \\
\hline$\%$ No Use & $\begin{array}{c}63.90 \\
(87.00)\end{array}$ & $\begin{array}{c}81.10 \\
(95.30)\end{array}$ & 45.00 & 68.20 \\
\hline
\end{tabular}

$\mathrm{M}=$ Mean; SD = Standard Deviation; \% No Use = Percentage of adolescents reporting no substance use intentions or behaviors. Bolded correlations are significantly different across $9^{\text {th }}$ and $12^{\text {th }}$ grade. Zero order correlations outside of parentheses, betas controlling for $7^{\text {th }}$ grade substance use variables inside of parentheses; Means, standard deviations, and $\%$ No Use for $7^{\text {th }}$ grade substance use variables in parentheses. $*=p<.05$. 